\title{
The sources of hospital cost variability
}

\author{
Brigitte Dormont $\mathrm{t}^{\mathrm{a}, \mathrm{b}, *}$ and Carine Milcent $\mathrm{t}^{\mathrm{b}, \mathrm{c}}$ \\ a Thema-CNRS, University of Paris10-Nanterre, France \\ ${ }^{\mathrm{b}}$ IEMS, Institute of Health Economics and Management, Lausanne, Switzerland \\ ${ }^{\mathrm{c}}$ Delta-CNRS, Ecole nationale Supérieure, Paris, France
}

\section{Summary}

Hospital heterogeneity is a major issue in defining a reimbursement system. If hospitals are heterogeneous, it is difficult to distinguish which part of the differences in costs is due to cost containment efforts and which part cannot be reduced, because it is due to other unobserved sources of hospital heterogeneity. In this paper, we apply an econometric approach to analyse hospital cost variability. We use a nested three-dimensional database (stayshospitals-years) in order to explore the sources of variation in hospital costs, taking into account unobservable components of hospital cost heterogeneity. The three-dimensional structure of our data makes it possible to identify transitory and permanent components of hospital cost heterogeneity. Econometric estimates are performed on a sample of 7314 stays for acute myocardial infarction (AMI) observed in 36 French public hospitals over the period 1994-1997. Transitory unobservable hospital heterogeneity is far from negligible: its estimated standard error is about $50 \%$ of the standard error we estimate for cost variability due to permanent unobservable heterogeneity between hospitals. Copyright (C) 2004 John Wiley \& Sons, Ltd.

JEL classification: C23; H51; 118

Keywords hospital costs; moral hazard; unobservable hospital heterogeneity; panel data

\section{Introduction}

Large variations in hospital costs are observed in several countries. In the US, the range from the 5 th to the 95th percentile of hospital Medicare standardised cost per case was $142 \%$ in 1985 [1]. In France, in 1996, the range from the standardised cost per case in the least expensive public hospital to the standardised cost per case in the most expensive public hospital amounted to $226 \%$ [2].

It is possible to interpret this variability as resulting from inefficiencies between hospitals. In France, many economists incriminate the current reimbursement system of public hospitals. Indeed, the global budget which was implemented in 1983 has led to large disparities in the financial burdens faced by hospitals. One solution would then be to address inefficiencies through an appropriate reimbursement policy, such as a Prospective Payment System per DRG.

In principle, prospective payment provides a strong incentive to keep costs down and avoid inefficiency [3,4]. However, a few years after the implementation of such a system for the Medicare patients in the US, some authors have pointed to the enormous remaining variations in hospitals costs and argue that some portion of hospital cost differences was justifiable $[1,5,6]$. As stated by Newhouse [7,8], reimbursement should not neces-

*Correspondence to: Thema UPX, Bâtiment G, 200 avenue de la république 92001, Nanterre Cedex, France.

E-mail: dormont@u-paris10.fr 
sarily be fully prospective. One has to take 'legitimate' cost heterogeneity into account, in order to avoid the risks of a fully prospective payment system, i.e. patient selection, lower care quality, creaming, skimping and dumping [1,6,8-11].

Analysing hospital cost variability is thus of major importance. It can make it possible to evaluate the relative importance of components of cost variability and to gauge inefficiency and the need for reimbursement policies that address inefficiencies, as opposed to compensating for variability in case-mix. To what extent does inefficiency influence cost variability? To what extent should patient and hospital heterogeneity be allowed for in a payment system? Answering these questions requires more knowledge about the sources of variation in hospital costs.

Except for a few cases (such as [12]) the studies about hospital costs use information about average cost at hospital level. For example, the recent panel data studies of Linna [13] and Rosko [14] about Finnish and US hospitals concern twodimensional databases recording observations relative to hospitals-years. We have at our disposal a three-dimensional nested database (stays-hospitals-years) that is sufficiently rich to disaggregate the components of hospital cost variation.

Many studies about hospital costs focus on the issue of efficiency. A common approach is based on the data envelopment analysis [13,15-17]. Other studies use stochastic frontier models $[13,14,18-20]$. Some of them focus on the additional cost due to specific activities of hospitals. For example, Lopez-Casanovas and Saez [21] estimated the extra cost for teaching hospitals in Spain. As stated by Linna [13], most studies of hospital efficiency can be criticized for not having measured output or even case-mix appropriately. In addition, most of the stochastic frontier studies have used cross-sectional data. The use of panel data in efficiency analysis makes it possible to specify the efficiency parameter as a parametric function of time or of explanatory variables $[22,23]$. Another advantage of panel data, pointed out by Schmidt and Sickles [24], is that they make it possible to avoid distributional assumptions. When inefficiency is assumed to remain constant over time, it can be specified as a hospital's specific effect, which can be treated as fixed or random. However, one limit of this approach is that it assumes that all unmeasured hospital heterogeneity is due to inefficiency [25].
The purpose of this paper is to explore the sources of hospital cost variability in France. We take advantage of a three-dimensional nested database (stays-hospitals-years) of 7314 stays for acute myocardial infarction observed in 36 French public hospitals over the period 1994-1997. Information is recorded at three levels: stays are grouped within hospitals and hospitals are observed over several years. The available information makes it possible to evaluate the respective influences of observable patient characteristics and hospital characteristics on cost variability. In addition, the complex structure of our panel data allows us to identify two components of unexplained cost variability: short-term unobserved hospital heterogeneity and permanent unobserved hospital heterogeneity.

The remainder of this article is organized as follows. In the next section, we describe the data, characterizing the stays, the observed pathologies, as well as the hospitals in the database. The following section defines econometric specifications that make it possible to analyse costs and identify the components of cost variability. The penultimate section presents econometric methods, specification tests and the results of the econometric application. We conclude in the last section.

\section{Description of the data}

We have at our disposal a sample of 7314 stays for acute myocardial infraction (AMI) observed in 36 French public hospitals over the period 1994 1997. In France and in the present study, the term 'public hospitals' stands for hospitals belonging to the public sector as well as most of the private-notfor-profit hospitals. In France, public hospitals account for most of the total admissions (2/3 of admissions for AMI). Our sample has been extracted from the PMSI cost database. PMSI stands for the Programme de médicalisation des systèmes d'informations, which collects information about hospital activity. Classification of stays by Diagnosis Related Group (DRG) is performed on the basis of diagnoses and procedures implemented during the stay. Within a prospective payment system, the regulator would define payments for each DRG. In order to obtain a high degree of patient homogeneity in terms of pathologies we selected patients aged at least 40 years with acute myocardial infraction (AMI) as 
the main diagnosis and grouped in the same DRG: uncomplicated AMI (DRG 179).

For each stay, we have information about the cost of the stay, secondary diagnoses, procedures implemented, entry mode into the hospital (coming from home or transferred from another hospital), discharge mode (return home or transfer), length of stay, age and gender of the inpatient.

The database gives access to rich and detailed information about stays. However, the information about services provided is rather limited. We cannot follow the same inpatient through successive hospital stays. There is no information about the patient's quality of life after the stay, about readmission just after the observed stay, about infections contracted during the stay. In addition, we have no information about the quality of services provided in terms of comfort or alleviation of pain.

Participation in the cost database program is optional. The number of participating hospitals is limited. They consent to give detailed information about their costs, which means that they have accounting systems which enable them to give such information. Using an exhaustive database of AMI patients with no information about costs, we have carried out a comparative analysis about patient characteristics and procedures implemented. This allows us to consider that our data are representative of AMI stays in French hospitals.

Our panel data exhibit a rather complex structure. Information is recorded at three levels: stays are grouped within hospitals and hospitals are observed over several years. The panel is unbalanced in several dimensions: not only does the number of stays recorded vary across hospitals for a given year but also the length of the observation period varies across hospitals. Basic features of the data are presented below. We first examine stays (the lowest level of observation), then we consider hospitals.

\section{Patients}

Most AMI patients $(64.3 \%)$ are grouped in DRG 179 (uncomplicated AMI). Together with drug therapy (aspirin, beta blockers, etc.), uncomplicated AMI patients can receive various treatments such as thrombolytic drugs, cardiac catheterization (hereafter denoted as CATH) and percutaneous transluminal coronary angioplasty (PTCA).
Catheterization is a specialized procedure used to view the blood flow to the heart in order to improve the diagnosis. Angioplasty (PTCA) appeared more recently than bypass surgery. It is an alternative, less invasive procedure for improving blood flow in a blocked artery.

In France, the use of an innovative procedure such as catheterization or angioplasty do not lead to classification of a stay into a specific DRG. This is rather different from the US classification, where stays with angioplasty are grouped in a specific DRG (DRG 112). These innovative procedures are most often performed within DRG 179: 76.1\% of CATHs and $82.8 \%$ of PTCAs implemented for AMI patients are implemented within DRG 179. Since they do not lead to a classification of the stay in a specific DRG, these costly procedures would not lead to a specific payment within the context of a prospective payment system. A payment system which does not take these procedures into account would therefore penalise the innovative hospitals which use them and give hospitals incentives to select patients.

Basic features of the data are presented in Table 1. Most of the patients are men. They are rather young. Eighty-nine percent of patients come from home, $64 \%$ of discharges are performed to return home and $36 \%$ are transfers to another hospital. AMI with death are grouped in another DRG (GHM 180). The average death rate for all AMI patients is about $9 \%$. Catheterization and angioplasty are implemented for, respectively, 38 and $12 \%$ of stays classified in DRG 179.

\section{Hospitals}

Stays are recorded for 36 hospitals, over the period 1994-1997 (Table 2). Not all the hospitals are observed over the whole period.

A sizeable proportion of hospitals never perform catheterization or angioplasty. These procedures require specific abilities and high-tech facilities. We have introduced a dummy variable for the innovative hospitals. For a given year, a hospital is considered innovative if it has performed catheterization for at least $2 \%$ of the stays, or at least one angioplasty (with or without stent). On the basis of this definition, 20 hospitals are classified as innovative and these hospitals account for $71.5 \%$ of the recorded stays (Table 2).

To complete our database, we have also recorded information about hospital type from 
the SAE survey (the 'Statistique Annuelle des Etablissements de santé' (SAE) is an annual survey which covers all French public hospitals.). There are three types of hospitals: a CHR (Centre

Table 1. Patient characteristics

\begin{tabular}{|c|c|c|}
\hline & $\begin{array}{l}\text { Number } \\
\text { of stays }\end{array}$ & $\begin{array}{l}\text { Proportion } \\
(\%)\end{array}$ \\
\hline \multicolumn{3}{|l|}{ Gender } \\
\hline Men & 5400 & 73.8 \\
\hline Women & 1914 & 26.2 \\
\hline \multicolumn{3}{|l|}{ Age } \\
\hline $40-64$ & 1861 & 25.4 \\
\hline $65-74$ & 2733 & 37.4 \\
\hline $75-84$ & 2271 & 31.1 \\
\hline 85 and over ${ }^{a}$ & 449 & 6.1 \\
\hline \multicolumn{3}{|l|}{ Length of stay } \\
\hline One day & 439 & 6.0 \\
\hline Between 2 and 7 days & 2460 & 33.6 \\
\hline Between 8 and 14 days & 3234 & 44.2 \\
\hline Over 14 days & 1181 & 16.2 \\
\hline \multicolumn{3}{|l|}{ Admission } \\
\hline Home & 6493 & 88.8 \\
\hline Other hospital & 821 & 11.2 \\
\hline \multicolumn{3}{|l|}{ Discharge } \\
\hline Other hospital & 2612 & 35.7 \\
\hline Home & 4702 & 64.3 \\
\hline \multicolumn{3}{|l|}{ Procedures } \\
\hline CATH & 2788 & 38.1 \\
\hline PTCA & 853 & 11.7 \\
\hline Stent & 374 & 5.1 \\
\hline
\end{tabular}

Cost Database: 7314 stays, 1994-1997.

${ }^{\text {a }}$ Patients aged of 100 years and over have been removed from our sample.
Hospitalier Regional.) is a public teaching hospital which also carries out research; a PRIV is a private not for profit hospital (PRIV hospitals have only recently been regulated through the global budget system and only partially so); PUB refers to other public hospitals. Table 3 shows that all the CHR and most of the PRIV are innovative hospitals.

Other indicators are available in the SAE survey, such as number of beds, occupation rate of beds, diversification of activities within the hospital. However, a lot of missing observations prevent us to carry out a complete descriptive analysis. On a restricted number of observations, we find that CHRs are large hospitals with highly diverse activities. On the other hand, private not for profit hospitals (PRIVs) concentrate their services on a small number of activities.

We tried to find empirical evidence of a link between hospital size (and diversification of activities) and the level of costs, but did not obtain significant results.

Table 4 shows correlation coefficients between hospital type, the dummy variable INNOV and averaged indicators computed at the hospital-year level (95 observations). INNOV indicates that the hospital is innovative and can vary over time: a hospital can be non-innovative one year, and perform high-tech procedures the year after. CHRs are innovative and have a low rate of discharge through transfer to another hospital. Private not for profit hospitals (PRIV) are characterized by a high rate of use of innovative procedures and a high rate of admission through transfer from another hospital. Other publics hospitals are rather non innovative and are characterized by a small rate of use of innovative procedures. Patient flows towards innovative hospitals appear clearly in (i) the positive correla-

Table 2. Hospitals of the cost database

\begin{tabular}{lcccc}
\hline Years & $\begin{array}{c}\text { Number of } \\
\text { hospitals }\end{array}$ & $\begin{array}{c}\text { Whose } \\
\text { innovative } \\
\text { hospitals }\end{array}$ & $\begin{array}{c}\text { Number of } \\
\text { stays }\end{array}$ & $\begin{array}{c}\text { Share \% of stays in } \\
\text { innovative } \\
\text { hospitals }\end{array}$ \\
\hline 1994 & 21 & 12 & 1669 & 70.2 \\
1995 & 27 & 16 & 2028 & 69.7 \\
1996 & 17 & 10 & 1267 & 78.3 \\
1997 & 30 & 2350 & 70.5 \\
$1994-1997$ & 36 & $20^{\text {a }}$ & 7314 & 71.5 \\
\hline
\end{tabular}

Cost Database: 7314 stays, 1994-1997. Patients aged of 100 years and over have been removed from our sample.

${ }^{\text {a }}$ These hospitals are innovative hospitals on all their years of presence in the sample. 
Table 3. Innovative and non-innovative hospitals

\begin{tabular}{lccr}
\hline & Innovative & Non-innovative & $\begin{array}{c}\text { Total } \\
\text { (hospitals } * \text { years) }\end{array}$ \\
\hline CHR (Teaching hospital) & 9 & 0 & 9 \\
PUB (Other public hospital) & 35 & 35 & 70 \\
PRIV (Private not for profit) & 12 & 4 & 16 \\
Total & 56 & 39 & 95 \\
\hline
\end{tabular}

Cost Database: 7314 stays, 1994-1997.

Table 4. Correlation coefficients between average hospital characteristics

\begin{tabular}{lcccccrrr}
\hline & INNOV & TI & TX & MLOS & MCATH & \multicolumn{2}{c}{ MPTCA } & MSTENT \\
\hline CHR & 27.0 & ns & -39.6 & $19.8^{*}$ & 32.3 & \multicolumn{1}{c}{ ns } & ns \\
PUB & -30.4 & -29.9 & 30.7 & ns & -58.2 & -51.9 & -32.9 \\
PRIV & ns & 45.0 & ns & ns & 43.3 & 54.5 & 40.1 \\
INNOV & 100 & ns & -45.1 & 25.5 & 73.7 & 35.7 & 24.8 \\
\hline
\end{tabular}

95 Hospital $*$ years from the costdatabase; ns: non-statistically significant correlation coefficient $(P<0.05)$.

* The correlation coefficient is significant at $5.44 \%$.

The following variables are recorded in the SAE database or computed for the 95 hospitals * years of the cost database (1994-1997): CHR, Regional Hospital Center (teaching and research activity); PUB, other public hospital; PRIV, private not for profit hospital; INNOV, innovative hospital (i.e. having the ability to perform a PTCA or a CATH); TI, admission rate of patients being transferred from another hospital (average per hospital and per year); TX, discharge rate of patients being transferred to another hospital (average per hospital and per year); MLOS, length of stays (average per hospital and per year); MCATH, CATH rate (average per hospital and per year); MPTCA, PTCA rate of patient (average per hospital and per year); MSTENT, STENT rate of patient (average per hospital and per year).

tion coefficients we find between admission rate through transfer and CATH or PTCA rates; (ii) the negative correlation coefficients we find between discharge rate through transfer and $\mathrm{CATH}$ rate.

\section{Costs}

Historical context. In France, public hospital budgets have been based on a global budget system for more than 10 years, including the period 1994-1997 that we study. A complete information system which classifies inpatient stays by DRG has been set up, but a PPS has not been implemented. No real attempt at reform was undertaken from 1994 to 1997 (a gradual introduction of a PPS is planned for 2004). Budgets have no direct link to the actual production of hospitals. Hospitals are managed by conventional salaried administrators and do not keep the gains resulting from cost-reducing efforts. In addition, they are more or less subject to a soft budget constraint. This regulation has led to inequity and inefficiency in the allocation of resources [26].
In our sample, we have detailed information about costs per stay. These costs result from an activity financed on the basis of a global budget system, as it has been implemented in France.

Average costs. Table 5 gives average costs. The average cost per stay is equal to 4198 Euros with a standard error of 2863 Euros. On average, a stay is more costly when an innovative procedure has been implemented. As concerns hospital characteristics, stays are more expensive in teaching and in private not for profit hospitals. The stays are also costlier in innovative hospitals.

\section{Econometric specifications}

\section{Specification of the cost function}

Our observations are at the individual level of hospital stays. Therefore, our approach is different from papers which evaluate efficiency using data relative to average costs per hospital. A survey of 
Table 5. Average costs (Euros)

\begin{tabular}{lc}
\hline $\begin{array}{l}\text { Overall mean } \\
\text { (standard error) }\end{array}$ & $\begin{array}{c}\text { Average costs (Euros) } \\
4198 \\
(2863)\end{array}$ \\
\hline Men & 4141 \\
Women & 4398 \\
$40-64$ & 4104 \\
$65-74$ & 4233 \\
$75-84$ & 4480 \\
85 and over & 4155 \\
& \\
With CATH & 5099 \\
With PTCA & 5740 \\
With STENT & 5978 \\
Without procedure & 3666 \\
& \\
Teaching hospital (CHR) & 5205 \\
Private not for profit (PRIV) & 4630 \\
Other public hospital (PUB) & 3816 \\
& \\
Innovative hospital & 4453 \\
Non-innovative & 3592 \\
\hline
\end{tabular}

this literature can be found in [13]. A few American studies focus like us on a more disaggregated approach, using data at the patient level [12,27-29]. However, unlike French data, American data record charges per stay instead of cost per stay.

As stated above, the costs we observe result from activity financed on the basis of a global budget system. Cost variability is therefore influenced by several factors: (i) patient characteristics, (ii) hospital characteristics (infrastructure, economies of scale, economies of scope), (iii) inefficiency (which is more or less possible, depending on the generosity obtained by the hospital manager from the regulator when bargaining for the budget), (iv) care quality (which affects mainly the permanent unobserved heterogeneity).

Let us denote $C_{i, h, t}$ the cost of stay $i$ in hospital $h$ during the year $t$. We consider the following model:

$$
\begin{aligned}
C_{i, h, t}= & X_{i, h, t}^{\prime} \gamma_{t}+W_{h, t}^{\prime} \alpha+Q_{h}^{\prime} \lambda+a+c_{t}+\eta_{h} \\
& -\varepsilon_{h, t}+u_{i, h, t}
\end{aligned}
$$

$X_{i, h, t}^{\prime}$ represents individual patient characteristics, such as cross effects age $\times$ gender, admission and discharge modes, length of stay. The explanatory variables $W_{h, t}^{\prime}$ and $Q_{h}^{\prime}$ are observable hospital characteristics: the type (teaching, private not for profit or other public hospital), whether the hospital is innovative or non-innovative (see the definition of an innovative hospital in the 'Hospitals' section), implementation rate of hightech procedures, rates of admission or discharge through transfer. $a$ is a constant.

We have chosen a linear specification for the cost function. The dependent variable is $C_{i, h, t}$ and not $\log \left(C_{i, h, t}\right)$. It is well known that health care expenditures generally have a very asymmetric distribution. In our case, however, the distribution is truncated on the right because of the selection of stays grouped in DRG 179 (uncomplicated AMI). More costly stays are grouped in other DRGs: complicated AMI or AMI treated by bypass surgery. Therefore, the tests (skewness and kurtosis) we have carried out on the distribution of $C_{i, h, t}$ have led us to the conclusion that it is closer to a normal than to a lognormal distribution.

Given patient characteristics, cost variability can stem from hospital characteristics such as hospital type (CHR, PRIV, PUB) and size, diversification of activities, quality of services provided (performance of innovative procedures, comfort, alleviation of pain), skill level of nurses and doctors, quality of hospital management. Some of these factors are observable, some of them cannot be observed.

The observable characteristics for the patients are the variables $X_{i, h, t}^{\prime}$, and for the hospitals the variables $W_{h, t}^{\prime}$ and $Q_{h}^{\prime}$.

\section{Unobserved hospital heterogeneity}

Given the observable characteristics, cost variability depends, in specification (1), on the term:

$c_{t}+\eta_{h}-\varepsilon_{h, t}+u_{i, h, t}$

$c_{t}$ is a fixed temporal effect which can be linked to technological progress, the pace of price growth and the general trend of hospital budgets.

We take into account unobservable patient heterogeneity with the random error term $u_{i, h, t}$, which is assumed to be iid $\left(0, \sigma_{u}^{2}\right) . \varepsilon_{h, t}$ is a perturbation supposed to be iid $\left(0, \sigma_{\varepsilon}^{2}\right)$ and uncorrelated with $u_{i, h, t}$.

(a) Interpretation of hospital-specific effects $\eta_{h}$. Unobservable hospital heterogeneity is specified by hospital-specific effects $\eta_{h}$, which can be assumed to be random or fixed. 
$\eta_{h}$ can be seen as the result of three components. (i) A productivity parameter that is assumed to be time-invariant: the hospital's activity is more or less costly, depending on its infrastructure or on the existence of economies of scale or of scope. (ii) Long-term moral hazard: the hospital management can be permanently inefficient. (iii) A term taking into account the time-invariant quality of care services.

(b) Interpretation of $\varepsilon_{h, t}$. The perturbation $\varepsilon_{h, t}$ is defined as the deviation, ceteris paribus, for a given year, of hospital $h$ 's cost in relation to its average cost.

$\varepsilon_{h, t}$ is influenced by omitted variables and measurement errors, which are the ordinary components of any perturbation. But measurement errors are likely to be of slight importance. Indeed, $\varepsilon_{h, t}$ is replicated for each stay in the same hospital $h$ during the same year $t$. Within this framework, a measurement error can only come from a systematic error in patient registration, or an error in hospital classification. These two possibilities are unlikely. Indeed, the process of building of the PMSI database, as well as checking of these data by the Ministry of Health, prevent such errors from being replicated systematically.

Let us turn now to the other possible components of $\varepsilon_{h, t}$, i.e. the omitted variables. $\varepsilon_{h, t}$ can be seen as the result of two components:

- transitory cost reduction efforts, i.e. transitory moral hazard. For instance, the manager can be more or less rigorous when bargaining prices for supplies or for services delivered to the hospital by outside firms.

- Transitory shocks which affect hospital $h$ in a given year $t$. Indeed, $\varepsilon_{h, t}$ can be influenced by transitory shocks such as, for instance, an electrical failure. Notice that these shocks are likely to be observable. In addition, they are rather rare.

In principle, $\varepsilon_{h, t}$ could also reflect transitory variations in quality. However, the civil servant status of most employees of public hospitals induces rigidity in the work organization and human resources management. The staff of the public hospitals is assigned to a unit. It cannot be rapidly switched from one unit to another one. Similarly, facilities cannot be modified very quickly, since most decisions are taken by a central public administration. Therefore, changes in care quality do not take place quickly. Given the fact that our data covers only 4 years, it is not unreasonable to rule out the possibility of significant upgrading or deterioration of quality.

On the whole, $\varepsilon_{h, t}$ is influenced by transitory moral hazard and transitory shocks. The influence of the latter is likely to be rather small. However, since we cannot evaluate its magnitude, we cannot ignore it.

\section{Estimation and results}

\section{Econometric methods}

In model (1) the hospital specific effects $\eta_{h}$ can be assumed to be random or fixed.

Assuming that $\eta_{h}$ is random comes down to assuming that unobserved heterogeneity has an influence on costs only at the level of second-order moments (on their variance) and is not correlated with observed characteristics $X_{i, h, t}^{\prime}, W_{h, t}^{\prime}$ and $Q_{h}^{\prime}$. One has:

$$
\begin{aligned}
C_{i, h, t}= & X_{i, h, t}^{\prime} \gamma_{t}+W_{h, t}^{\prime} \alpha+Q_{h}^{\prime} \lambda+a+c_{t} \\
& +\underbrace{\eta_{h}-\varepsilon_{h, t}+u_{i, h, t}}_{v_{i, h, t}}
\end{aligned}
$$

with $\eta_{h}$ iid $\left(0, \sigma_{\eta}^{2}\right)$.

Estimation methods are not straightforward for two reasons: (a) our error component model exhibits a nested (hierarchical) structure since the perturbation is written as: $v_{i, h, t}=\eta_{h}-\varepsilon_{h, t}+u_{i, h, t}$; (b) our panel data is unbalanced: not only does the number of stays recorded vary across hospitals for a given year but also the length of the observation period varies across hospitals. Therefore, our model is different from the unbalanced nested error component model considered by Baltagi et al. [30]. For our case, Antweiler [31] shows that data cannot be easily moulded into a feasible generalized least squares transformation for OLS estimation and that maximum likelihood estimation (MLE) provides a suitable alternative. Under the assumption of normality, a consistent and efficient estimator is given by this MLE.

One can also assume that $\eta_{h}$ is a fixed effect. In this case, the model includes hospital dummies (to estimate the fixed effects $\eta_{h}$ ) and it is not possible to identify the parameters $\lambda$. A consistent and 
efficient estimator is given by the FGLS applied to the following model:

$$
C_{i, h, t}=X_{i, h, t}^{\prime} \gamma_{t}+W_{h, t}^{\prime} \alpha+a+c_{t}+\eta_{h} \underbrace{-\varepsilon_{h, t}+u_{i, h, t}}_{\xi_{i, h, t}}
$$

\section{Specification tests}

Hospital specific effects $\eta_{h}$ take unobservable hospital characteristics (long-term moral hazard, infrastructure, care quality) which can be correlated with explanatory variables, into account. For instance, care quality may be higher in a teaching hospital. In order to test for the independence of $\eta_{h}$ and to examine whether hospital specific effects are fixed or random, we have used a specification test which is an extension of the test proposed by Mundlak [32] for the standard error component model. We assume that a correlation between $\eta_{h}$ and the explanatory variables can be written as a regression of the form: $\eta_{h}=X_{., h, .}^{\prime} \pi_{1}+W_{h, .}^{\prime} \pi_{2}+\beta_{h}$, where $\beta_{h}$ is iid $\left(0, \sigma_{\beta}^{2}\right)$ and assumed to be uncorrelated with $\varepsilon_{h, t}$ nor with $u_{i, h, t}$. In this framework, the independence test of $\eta_{h}$ is equivalent to the test for $H_{0}: \pi_{1}=\pi_{2}=0$ in the model:

$$
\begin{gathered}
C_{i, h, t}=X_{i, h, t}^{\prime} \gamma_{t}+W_{h, t}^{\prime} \alpha+X_{., h, .}^{\prime} \pi_{1}+W_{h, .}^{\prime} \pi_{2} \\
+a+c_{t}+\underbrace{\beta_{h}-\varepsilon_{h, t}+u_{i, h, t}}_{\zeta_{i, h, t}}
\end{gathered}
$$

This test leads us to reject the hypothesis of independence between $\eta_{h}$ and the explanatory variables (Table $7 b$ ). Therefore, we will prefer model (3), where $\eta_{h}$ is fixed. This model is a standard error component model, with a perturbation equal to $-\varepsilon_{h, t}+u_{i, h, t}$. In this case, feasible generalized least squares lead to a consistent and asymptotically efficient estimate if $\varepsilon_{h, t}$ is not correlated with the explanatory variables. A Hausman test allowed us to validate the hypothesis that the effects $\varepsilon_{h, t}$ are random and not correlated with the explanatory variables (Table 7b).

The tests described above are relevant if the explanatory variables are also uncorrelated with the perturbation $u_{i, h, t}$. This perturbation reflects patient characteristics which are unobservable for the econometrician, but can be observed by the doctor and therefore influence the cost of the stay. The explanatory variables are not exogenous if they are correlated with these characteristics. For example, the patient's preferences or risk adversion can influence the length of the stay. Various Hausman tests have allowed us to validate the hypothesis that the variables $X_{i, h, t}^{\prime}$ and $W_{h, t}^{\prime}$ are exogenous (Table 7b). Thus, model (3) can be consistently estimated by the FGLS.

\section{Results}

Tables 6 and 7 present the estimates of models (2) and (3), and the associated specification tests.

Two specifications, related to different lists of explanatory variables $Q_{h}$ and $W_{h t}$ for the hospital characteristics, were estimated. Model (A) includes indicators close to verifiable characteristics such as hospital type, the variable indicating whether or not the hospital is innovative and average rates of admission and discharge through transfer. Model (B) includes additional variables such as rates of use of innovative procedures, which can be more directly decided on by the hospital.

In order to simplify our presentation, we do not report in Table 7 the estimated coefficients of the individual characteristics $X_{i, h, t}^{\prime}$ : indeed the various cross-effects have led to a total number of 32

Table 6. Influence on cost of patient characteristics, length of stay and time (Euros)

Estimated coefficient

\section{Age * sex}

Man: 40-64 years

Man: 65-74 years

Man: 75-84 years

Man: 85 years and over

Woman: 40-64 years

Woman: $65-74$ years

Woman: $75-84$ years

Woman: 85 years and over

Reference

$-221.0^{*}$

$-540.0^{*}$

$-1098.4^{*}$

$-396.9^{*}$

$-426.3^{*}$

$-719.3^{*}$

$-1326.4^{*}$

Length of stay

$378.2^{*}$

Time dummies

Year 1994

Year 1995

Year 1996

Year 1997

Reference

$260.5^{* *}$

$768.6^{*}$

$583.5^{*}$

Cost Database: 7314 stays, 1994-1997.

* The coefficient is significant $(5 \%)$.

*** The coefficient is significant $(1 \%)$.

Estimation by feasible generalized least square (residuals: $-\varepsilon_{h, t}+u_{i, h, t}$ ) for a model with fixed hospital effect $\eta_{h}$. 
variables. In order to give an idea of the influence on costs of individual characteristics, of time dummies and of the length of the stay, we report in Table 6 the estimation of a simpler model, where cross-effects have been reduced to age $x$ gender effects. The results are quite similar to those of a model comprising all the detailed crosseffects, but they are easier to read. One additional day induces, ceteris paribus, an average additional cost of about 380 Euros. The influence of individual stay characteristics confirms the results generally obtained in studies of stays for acute myocardial infarction. The most costly stays are observed for men. In addition, cost is a decreasing function of age. This latter result may seem surprising because older patients are generally in poorer health. Actually, this is due to the fact that they receive fewer procedures, a fact that is well documented in the medical literature [34,35].

The estimation of an incomplete specification using only individual patient characteristics $X_{i, h, t}^{\prime}$ as explanatory variables reveals that $54.2 \%$ of cost variability can be explained by observable patient heterogeneity. Addition of observable hospital characteristics $W_{h, t}^{\prime}$ and $Q_{h}^{\prime}$ to this specification led to $68.9 \%$ explained cost variability.

The likelihood ratio test leads us to reject the hypothesis that hospital specific effects $\eta_{h}$ are

Table 7. Cost function estimates (Euros)

(a)

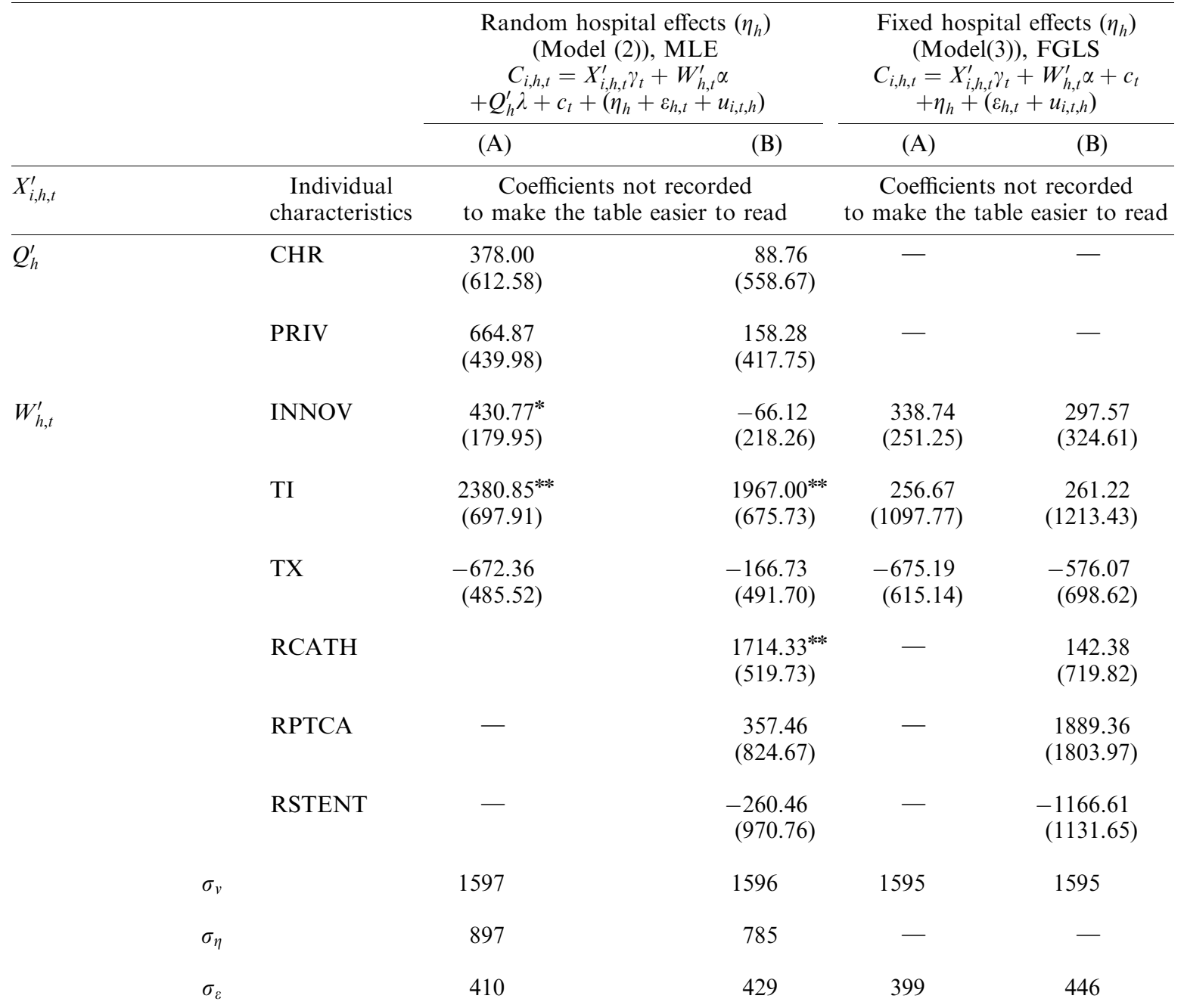


Table 7 (continued)

(b) Statistics and tests

(A)

(B)

(A)

(B)

Log likelihood
Likelihood ratio test
$\left(P>\chi^{2}\right)^{\mathrm{a}}$

$-44506.42$

$-44497.11$

7246

$(0.000)$

$(0.000)$

68.5

68.5

$\left(P>\chi^{2}\right)^{\mathrm{a}}$

71.8 Hausman test ${ }^{\mathrm{b}}$ for

$\left(P>\chi^{2}\right)$

13005

$(0.000)$

12913

Likelihood ratio test for

67.2 independence of $\varepsilon_{h, t}$

$\left(P>\chi^{2}\right)$

$(0.0003)$

$(0.0005)$

$\left(P>\chi^{2}\right)$

30.8

$(0.5255)$

Cost Database: 7314 stays, 1994-1997.

All the estimations have year dummies.

*** The coefficient is significant $(1 \%)$.

*The coefficient is significant $(5 \%)$. CHR, teaching hospital (public); PRIV, private, not-for-profit hospital; INNOV, innovative hospital; TI, admission rate through transfer for hospital $h$, in year $t$; TX, discharge rate through transfer for hospital $h$, in year $t$; RCATH, rate of in-hospital catheterization use for hospital $h$, in year $t$, RPTCA; rate of in-hospital percutaneous transluminal coronary angioplasty use for hospital $h$, in year $t$, RSTENT, rate of in-hospital stent use for hospital $h$, in year $t$.

${ }^{\text {a }}$ Significance level.

${ }^{\mathrm{b}}$ The usual statistics of the Hausman test eliminates automatically the variables $W_{h, t}^{\prime}$. So, there is no difference between the tests on models $\mathrm{A}$ and $\mathrm{B}$. This test is equivalent to a test for independence between $X_{i, h,}^{\prime}$ and $\varepsilon_{h, t}$. To test for the exogeneity of $W_{h, t}^{\prime}$ we have used another Hausman's specification test that compares an estimator that is known to be consistent and efficient under the null and alternative hypotheses (here, the error component two-stage least square estimator, EC2SLS [33] with an estimator which is efficient under the null hypothesis (here, feasible generalized least squares estimator, FGLS). Instruments are the patient demographic characteristics and the fully-interacted of the secondary diagnoses, gender and age of the patient. The test provides evidence that we cannot reject the null hypothesis: the variables $W_{h, t}^{\prime}$ and $X_{i, h, t}^{\prime}$ are exogenous.

random. However, the results obtained on both specifications (2) and (3) are worthy of comment. We will then focus on the fixed effects model.

Estimated coefficients of observable hospital characteristics are reported in Table 7. The estimates of the random effects model show that costs of teaching hospitals (CHR) and costs of private not for profit hospitals (PRIV) do not differ significantly from those of other public hospitals. This result seems rather surprising: the French hospital administration [36] evaluates a $13 \%$ extra cost for teaching hospitals; for teaching hospitals in Spain, Lopez-Casasnovas and Saez [21] estimated, using a rather different method, a significant extra cost of about $9 \%$. As regards PRIV hospitals, the French federation of private not for profit hospitals declares that wages are $14 \%$ higher in their sector, inducing $7 \%$ higher costs [37].

On the other hand, the estimate of the random effect model leads to a positive and significant influence (431 Euros) of the capacity to implement innovative procedures (INNOV). Comparing this coefficient to the average cost of a reference AMI stay (4198 Euros), we obtain an extra cost of $10.2 \%$ for innovative hospitals. This positive effect appears when estimating model $\mathrm{A}$, but becomes negative with the estimation of model $\mathrm{B}$, where rates of use of innovative procedures are part of its explanatory variables. Actually, the negative effect of INNOV is then totally counterbalanced by the positive coefficients of the rates of use. On the whole, being an innovating hospital always induces an extra cost. It is interesting to note that all the teaching hospitals (CHR) in our sample are innovative (Table 3 ). Since the variable $\mathrm{CHR}$ has no significant effect, our results therefore mean that hospitals which are innovative are more expensive than others, whether they are $\mathrm{CHR}$ or not: the extra cost is more directly linked to innovative activity than to hospital status.

The estimates of the random effect model lead also to a positive effect of the variable TI, indicating that hospitals which accept a high proportion of admissions through transfer have higher costs.

Our estimation procedure allows us to identify two components of the unexplained cost variability: transitory and permanent unobserved hospital heterogeneity. Indeed, the MLE leads to an estimation of $\sigma_{\eta}$, the standard error of the hospital specific effects $\eta_{h}$ when they are assumed to be 
random. And with MLE, we have also estimated $\sigma_{\varepsilon}$, the standard error of the perturbation $\varepsilon_{h, t}$. The influence of this transitory unobserved hospital heterogeneity on cost variability is far from negligible: its estimated standard error (410 or 428 ) is about $50 \%$ of estimated $\sigma_{\eta}(897$ or 785 ).

These results have to be confirmed because, as stated above, the hypothesis of random hospital effects is rejected by our specification test (Table 7b). Therefore, we now focus our comments on the estimates of the model where hospital effects $\eta_{h}$ are supposed to be fixed.

It is not possible to identify the influence of the constant variables $Q_{h}^{\prime}$ from the estimate of the fixed effects model. In addition, we do not find any significant effect of the variable INNOV, once we have taken permanent differences in average costs into account through the fixed effects.

The fixed hospital effects specification allows us to obtain consistent estimates of the terms $\eta_{h}, \varepsilon_{h, t}$ and of their standard errors $\sigma_{\eta}$ and $\sigma_{\varepsilon}$. The correlation between $\hat{\eta}_{h}$ and $\hat{\varepsilon}_{h, t}$ is very small $(-0.001$ for models $\mathrm{A}$ and $\mathrm{B})$ and not significant. The estimated value of $\sigma_{\varepsilon}$ is quite similar to the one estimated by the maximum likelihood estimator: 399 or 446 (models A or B). As regards $\sigma_{\eta}$, one finds estimates which are about 150 Euros larger: 1057 or 993 (models $\mathrm{A}$ or B). This difference can be interpreted as resulting from the effect of hospital type: though unsignificant, this influence was captured by the variables $Q_{h}^{\prime}$ in the random effects model. It is integrated in the $\eta_{h}$ in the fixed effects model. The magnitude of cost variability attributable to transitory moral hazard is still sizeable: $\sigma_{\varepsilon}$ is close to about $50 \%$ of $\sigma_{\eta}$.

To get an idea of the magnitude of the standard errors $\sigma_{\eta}$ and $\sigma_{\varepsilon}$, one can compare them to the standard error of stay costs: 2863 Euros (for an average cost equal to 4198 Euros). In graph 1 and 2 , we relate the estimated effects $\hat{\eta}_{h}$ and $\hat{\varepsilon}_{h, t}$ to the corresponding average cost per hospital $C_{., h}$, and average cost per hospital per year $C_{., h, t}$ (these graphs are shown for model A.). The observations have been sorted by increasing average cost. Hospital specific effects are linked to average costs per hospital but are far from explaining them entirely (graph 1). Graph 2 illustrates how regular the average costs are, in comparison to transitory unobserved heterogeneity fluctuations. The interpretation is the following. Average costs $C_{., h, t}$ reflect the allocated budgets. The current system

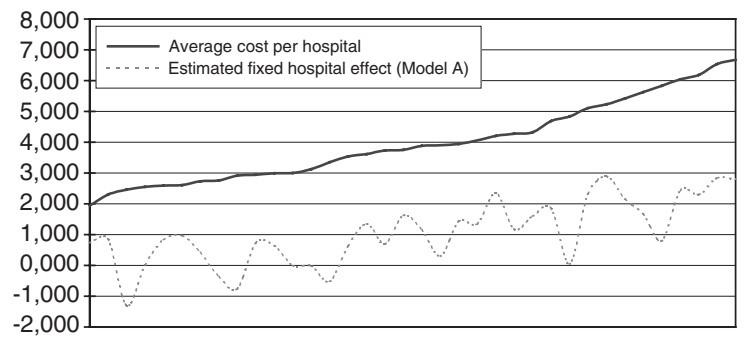

Graph 1.

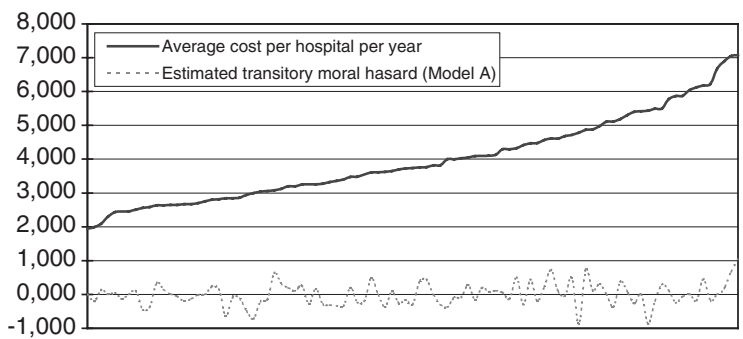

Graph 2.

gives hospitals fairly steady budgets. The gap between budgets and costs reflects transitory shocks or transitory moral hazard.

\section{Conclusion}

Hospital heterogeneity is a major issue in defining a reimbursement system. If hospitals are heterogeneous, the purchaser of health services (or the regulator) cannot distinguish between differences in costs due to cost containment efforts and differences which cannot be reduced, because they are due to other unobserved sources of hospital heterogeneity. In this paper, we have applied an econometric approach to explore the sources of variation in hospital costs.

Our estimates allow us to evaluate the influence on cost variability of observable patient and hospital characteristics.

We take hospital heterogeneity into account through observable hospital characteristics and unobserved hospital heterogeneity. Our estimates allow us to identify two components of this unobserved heterogeneity: a time-invariant component and a transitory component. 
This study makes it possible to assess the relative weights of the various causes of heterogeneity in the French public hospital costs. As regards observable characteristics, it shows the influence on costs of the use of innovative procedures. Turning to unobservable components of cost variability, our result highlight the magnitude of transitory unobserved heterogeneity. Its estimated standard error is about half of the standard error we estimate for cost variability due to permanent unobservable heterogeneity between hospitals.

If transitory shocks which affect the cost of all the stays in one hospital in a given year are very rare, it is possible to interprete this component as mainly due to transitory moral hazard. Indeed, given the management rules of French public hospitals, transitory variations in quality seem to us unlikely during a rather short period of time.

If this interpretation is correct, a payment system could be designed based on the conjecture that transitory unobserved hospital heterogeneity is entirely due to moral hazard. Such a payment system could induce significant budget savings, given the fact that a sizeable share of cost variability is explained by transitory unobserved hospital heterogeneity. However, this interpretation requires further investigations. One limitation of our results is that we cannot identify the share of transitory unobserved hospital heterogeneity that is due to transitory moral hazard. Access to data over a longer period is required to study this question more thoroughly.

\section{Acknowledgements}

We are grateful for the helpful comments of Werner Antweiler of the Faculty of Commerce, University of British Columbia, Alberto Holly, University of Lausanne, Michel Mougeot, University of Besançon, and Isabelle Durand-Zaleski, ANAES. We also thank the participants of the NBER Summer Institute workshop (Boston) for useful comments as well as the participants of the Crest-LEI and of the Delta seminar in Paris, Martin Chalkley and the participants of the twelfth European Workshop on Econometrics and Health Economics (Menorca). We are also grateful to two anonymous referees whose comments improved the paper. This study was funded in part by grants from the DREES (Direction de la Recherche, des Etudes, de l'Evaluation et des Statistiques) of the French Ministry of Labor and Solidarity.

\section{References}

1. Pope G. Using hospital-specific costs to improve the fairness of prospective reimbursement. $J$ Health Econ 1990; 9(3): 237-251.

2. Coca E. In Hôpital Silence! Les inégalités entre les hôpitaux, Berger-Levrault (ed.). Berger-Levrault: Paris, 1998.

3. Shleifer A. A theory of Yardstick Competition. RAND J Econ 1985; 16: 319-327.

4. Chalkley M, Malcomson JM. Government purchasing of health services. In Handbook of Health Economics, Culyer AJ, Newhouse JP (eds). vol. 1A, Chapter 15. North-Holland: Amsterdam, 2000; 847-890.

5. Keeler EB. What proportion of hospital cost differences is justifiable? J Health Econ 1990; 9(3): 359-365.

6. Goodall C. A simple objective method for determining a percent standard in mixed reimbursement systems. J Health Econ 1990; 9(3): 253-271.

7. Newhouse J. Frontier estimation: how useful a tool for health economics? J Health Econ 1994; 13: 317-322.

8. Newhouse JP. Reimbursing health plans and health providers: efficiency in production versus selection. J Econ Lit 1996; XXXIV: 1236-1263.

9. Ma ACT. Health care payment systems: cost and quality incentives. J Econ Manage Strategy 1994; 3(1): 93-112.

10. Ma ACT. Health care payment systems: cost and quality incentives-Reply. J Econ Manage Strategy 1998; 7(1): 139-142.

11. Ellis RP. Creaming, dumping, skimping: provider competition on the intensive and extensive margins. $J$ Health Econ 1998; 17: 537-555.

12. Kessler D, McClellan M. The effects of hospital ownership on medical productivity. RAND J Econ 2002; 33(3): 488-506.

13. Linna M. Measuring hospital cost efficiency with panel data models. Health Econ 1998; 7: 415-427.

14. Rosko MD. Cost efficiency of US hospitals: a stochastic frontier approach. Health Econ 2001; 10: 539-551.

15. Burgess J, Wilson P. Hospital ownership and technical inefficiency. Manage Sci 1996; 42: 110-123.

16. Magnussen J. Efficiency measurement and the operationalization of hospital production. Health Services Res 1996; 31: 21-37.

17. Seiford L. A DEA bibliography (1978-1992). In Data Envelopment Analysis: Theory, Methodology and Applications, Charnes A, Cooper W, Lewin A, Seiford L (eds). Kluwer Academic Publishers: Dordrecht, 1994; 437-469.

18. Wagstaff A. Estimating efficiency in the hospital sector: a comparison of three statistical cost frontier models. Appl Econ 1989; 21: 659-672. 
19. Zuckerman S, Hadley J, Lezzoni L. Measuring hospital efficiency with frontier cost functions. J Health Econ 1994; 13: 255-280.

20. Wagstaff A, Lopez G. Hospital costs in catalonia: a stochastic frontier analysis. Appl Econ Lett 1996; 3: 471-474.

21. Lopez-Casasnovas G, Saez M. The impact of teaching status on average costs in Spanish Hospitals. Health Econ 1999; 8(7): 641-651.

22. Battese G, Coelli T. Frontier production functions, technical efficiency and panel data: with application to paddy farmers in India. J Productivity Anal 1992; 3: $153-169$.

23. Battese G, Coelli T. A model for technical efficiency effects in a stochastic frontier production function for panel data. Empirical Econ 1995; 20: 325-332.

24. Schmidt P, Sickles RC. Production frontiers and panel data. J Bus Econ Stat 1984; 2: 367-374.

25. Hadley J, Zuckerman S. The role of efficiency measurement in hospital rate setting. $J$ Health Econ 1994; 13: 335-340.

26. Mougeot M. Régulation du système de santé, CAE, La Documentation Francaise, Paris, 1999.

27. McClellan M. Hospital reimbursement incentives: an empirical analysis. J Econ Manage Strategy 1997; 6(1): 91-128.

28. McClellan M, Newhouse J. The marginal costeffectiveness of medical technology: a panel instrumental variables approach. J Econ 1997; 77: 39-64.
29. Meltzer D, Chung J, Basu A. Does competition under medicare prospective payment selectively reduce expenditures on high-cost patients? RAND $J$ Econ 2002; 33(3): 447-468.

30. Baltagi BH, Song SH, Jung BC. The unbalanced nested error component regression model. J Econ 2001; 101: 357-381.

31. Antweiler W. Nested random effects estimation in unbalanced panel data. J Econ 2001; 101: 295-313.

32. Mundlak Y. On the pooling of time series and crosssection data. Econometrica 1978; 46: 69-85.

33. Baltagi BH. Simultaneous equations with error components. J Econ 1981; 17: 189-200.

34. Regueiro CR, Gill N, Hart A, Crawshaw L, Hentosz T, Shannon RP. Primary angioplasty in acute myocardial infarction: does age or race matter? J Thromb Thrombol 2003; 15(2): 119-123.

35. Rathore SS, Mehta RH, Wang Y, Radford MJ, Krumholz HM. Effects of age on the quality of care provided to older patients with acute myocardial infarction. Am J Med 2003; 114(4): 307-315.

36. Direction des Hôpitaux de Paris, mission PMSI. Le PMSI, analyse médico-économique de l'activité hospitalière, La lettre d'information hospitalières, 1996.

37. Apparitio S, Brocas A-M, Moisdon J-C. La place du PMSI dans l'allocation des ressources en île-deFrance, Agence Régional d'Hospitalisation d'île-deFrance. Rapport technique, 1999. 